\title{
Economic evaluation. Part 1: Introduction to the concepts of economic evaluation in health care
}

\author{
Emma Mclntosh, Ramon Luengo-Fernandez
}

\section{Introduction}

The past three decades have seen a rapid growth in the discipline of health economics, particularly in the area of economic evaluation of health care interventions. The aim of this article is to provide an introduction to the concepts of economic evaluation in health care, and the methodological issues pertaining to the identification, measurement and valuation of costs and benefits. In a subsequent article it will be shown how costs and benefits can be combined together in an economic evaluation framework. 1 The main established forms of economic evaluation will be described, and the reader will be introduced to the cost-effectiveness plane, a useful tool for reporting and presenting economic evaluation results. Throughout both articles particular reference to issues around family planning and reproductive health care will be made where possible.

\section{The importance of economic evaluation}

The main aim of health economics is to maximise the health of the population given the limited resources available. It is now an accepted paradigm that in order to make well-informed decisions about the best use of health services resources, health care consumers and policymakers must have information on both the costs and benefits associated with these decisions. It is only by combining the costs and benefits of alterative decisions or strategies within a systematic framework that such resource allocation decisions can be said to be 'well informed'

\section{Economic principles}

Central to the discipline of economics are the concepts of scarcity, choice and opportunity cost. Resources are scarce, thus every time we choose to use them in one way we give up the opportunity of using them in other ways, with the implication that priorities have to be set to guide resource allocation. Economic evaluation can be seen as a framework to assist in the optimal allocation of our scarce health care resources in order to maximise the health of society, by analysing the costs and benefits of alternative health care interventions. ${ }^{2}$ Economic evaluation methods should therefore be seen as a 'decision-aiding' instrument but not the only instrument to guide allocation of scarce health care resources. It should also be noted that society may have other goals when allocating resources ${ }^{3}$ such as equity or ethical issues, not only the goal of efficiency. This article begins by outlining the key issues arising in the identification and valuation of costs. The aim is to

J Fam Plann Reprod Health Care 2006; 32(2): 107-112 (Accepted 8 February 2006)

Health Economics Research Centre, University of Oxford, Department of Public Health, Oxford, UK

Emma McIntosh, MSc, PhD, Senior Research Officer

Ramon Luengo-Fernandez, MA, MSc, Research Officer

Correspondence to: Dr Emma McIntosh, Health Economics Research Centre, University of Oxford, Department of Public Health, Old Road Campus, Headington, Oxford OX3 7LF, UK. E-mail: emma.mcintosh@dphpc.ox.ac.uk introduce the reader to the important concepts in costing, such as opportunity cost, discounting and sensitivity analysis. This is followed by a section outlining important concepts in the measurement and valuation of benefits or 'outcomes' in health care. Box 1 provides a glossary of the economic evaluation terms used in this article. The second article in this two-part mini-series will outline the frameworks used to bring these costs and benefits together. ${ }^{1}$

Box 1: Strengths and weaknesses of the focus groups method

Cost-benefit analysis (CBA)

A type of economic evaluation where the effects are measured in monetary terms. The results of a CBA are usually expressed in terms of net benefit (benefit minus cost). CBA can consider individual projects on the basis of 'worthwhileness'.

Cost-effectiveness A type of economic evaluation where the effects analysis (CEA) are unidimensional health outcomes (e.g. number of number of surgical infections avoided, asthmafree days or a pain score). When combined with costs and compared to at least one comparator the results of CEA are often presented as a ratio of incremental cost over incremental effect.

Cost-utility

analysis (CUA)

A type of economic evaluation where the effects are estimated in utility units (e.g. QALYs). When combined with costs and compared to at least one comparator the results of CUA are presented in terms of incremental cost per QALY (i.e. as a ratio of incremental cost over incremental QALY).

Discounting

Discounting is a method used to account for individuals' time preference. Most individuals have a positive rate of time preference whereby benefits are preferred sooner rather than later and costs incurred later rather than sooner.

Economic A comparative analysis of at least two health evaluation interventions used to assess both the costs and consequences of the different health interventions, providing a decision framework.

The opportunity cost of investing resources in a Opportunity cost health care intervention is the benefit forgone from not using those resources in its best alternative use.

Quality-adjusted A QALY is a measure of health outcome that life year (QALY) combines quality of life with quantity of life (duration). Quality of life is usually estimated using utility weights, where each health state is valued on a scale from 0 (equivalent to death) to 1 (perfect health), corresponding to the healthrelated quality of life of that health state. These values are then aggregated across all health states and combined with the relevant duration of each health state to generate QALYs.

Sensitivity Sensitivity analysis is a means of representing analysis uncertainty in the results of economic evaluations. The four main types of sensitivity analysis are: one-way simple sensitivity analysis, multiway simple sensitivity analysis, threshold sensitivity analysis and probabilistic sensitivity analysis.

Stated preference A methodology based on the premise that any discrete choice good or service can be described by its attributes experiment (SPDCE) or characteristics. The extent to which an individual values that service or good will depend on the trade-offs made between levels of these attributes.

Willingness to pay The process in which individuals are asked the (WTP) maximum they are willing to pay, in monetary terms, to achieve a given benefit of an intervention/service. 


\section{HEALTH ECONOMICS}

\section{Costs}

\section{Opportunity costs}

The economic concept of cost is 'opportunity cost'. Opportunity cost takes as its conceptual starting point the premise that resources are scarce. Therefore, every time we choose to use resources in one way, we are giving up the 'opportunity' of using them in other potentially 'benefitgenerating' activities. The opportunity cost of any health care intervention is therefore defined as the benefit forgone from not using that resource in its best alternative use. Only if a resource has a next best use does it have an opportunity cost. Items to be included on the cost side of an economic evaluation are therefore any 'resources' that have an alternative use.

\section{Discounting}

Costs (and benefits) of health care interventions can occur at different times. For example, in prevention programmes costs are incurred early in the scheme whereas the benefits may stretch years into the future. Individuals generally prefer to incur costs in the future, and receive benefits sooner. Given this positive rate of time preference, costs that are incurred in the future should be given less weight (i.e. they should be discounted). The greater the preference for costs to occur in the future, the higher the discount rate will be. Currently, the National Institute for Health and Clinical Excellence (NICE) recommends a discount rate of $3.5 \%$. Using this discount rate, and from the middle column of the Appendix, $£ 1$ spent in Year 0 (i.e. those costs occurring now) is worth $£ 1, £ 1$ spent in Year 1 is equivalent to $£ 0.96$ pence now (or has a weight of 0.96 ), and so on. The further into the future costs and benefits occur, the less weight they are given.

\section{Sensitivity analysis}

Every evaluation will contain some degree of uncertainty, imprecision or methodological controversy and as a result assumptions will have to be made. ${ }^{5}$ What would the impact upon cost be if a midwife carried out the delivery of a baby rather than a consultant? What would be the effect on costs if postnatal stay was included in the cost of Caesarean section? What if a discount rate of $6 \%$ was used instead of $3.5 \%$ ? Sensitivity analysis allows the testing of the sensitivity of the results to the assumptions made and is therefore a means of representing uncertainty in the results of economic evaluations. Sensitivity analysis also allows for exploring the generalisability of results to other settings. The four main types of sensitivity analysis are: one-way simple sensitivity analysis (univariate analysis); multiway simple sensitivity analysis (scenario analysis); threshold sensitivity analysis (whereby the critical value of parameters above or below which the conclusions of the analysis will change are identified); and, finally, probabilistic sensitivity analysis (whereby probability distributions are assigned to the uncertain parameters and are incorporated into evaluation models based on decision analytical techniques, for example Monte Carlo simulation) ${ }^{4}$ For a comprehensive summary of the main types of uncertainty and the corresponding role of sensitivity analysis in addressing this see Briggs and Gray. 6

\section{Categorising resources to be included within economic evaluations}

Table 1 provides guidance on costs to be included in an economic evaluation. Staffing costs often comprise the largest component of health care resources. There will only be an opportunity cost of staff time if time released could be used in an alternative way (i.e. patient care).
Table 1 Guidance on costs to be included in an economic evaluation

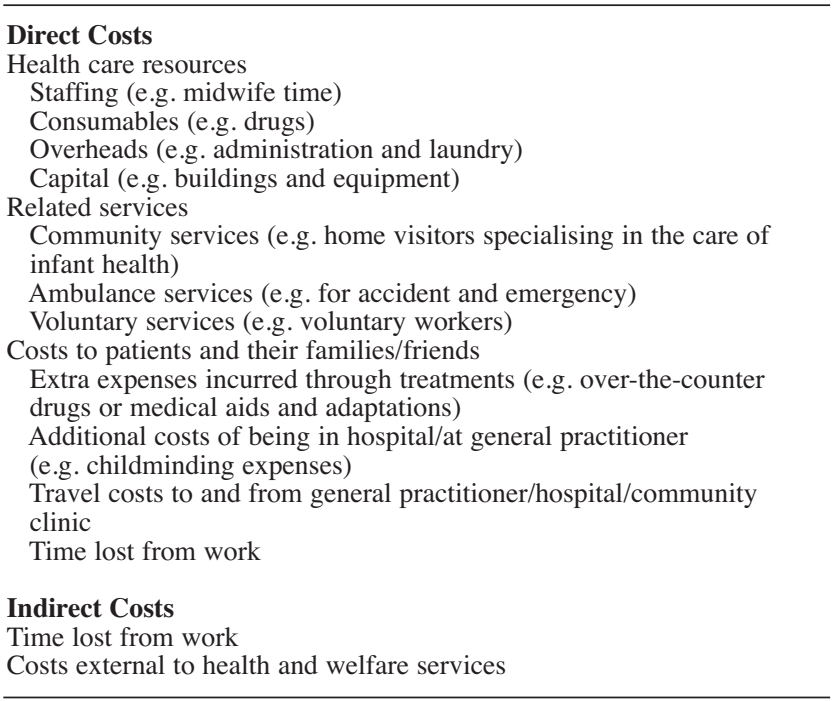

Consumables are items that are used for or on behalf of each patient such as drugs, dressings and disposable items such as sutures. Unit costs for consumables are usually readily available from national reference costs schedules, data sources and previously published studies. Overhead costs are those costs shared by more than one programme (e.g. heat and light, laundry, cleaning and administration). These services are provided centrally and costs are apportioned amongst the various sectors using various means. For a description of the various methods of overhead allocation see Drummond et al..$^{5}$ Capital items include land and buildings as well as items of equipment. Despite an initial outlay, the opportunity costs of capital are spread over their expected lifetime. One way of doing this is to calculate an equivalent annual cost (EAC). Using this method, the initial outlay on a capital asset is converted to an annual sum which, when paid over the estimated lifespan of the equipment, would equal the resources invested plus their opportunity cost. Equivalent annual costs are readily available (see final column in Box 2). For

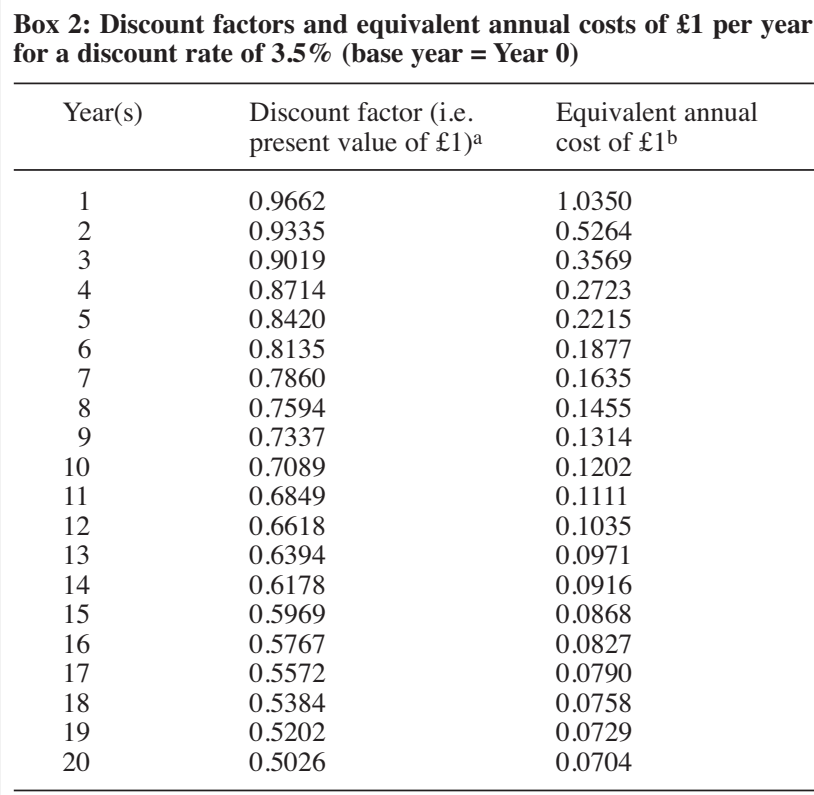

aThe discount factor is the percentage rate required to calculate the present value of future costs (or benefits). $D_{n}=1 /(1+r)^{n}$, where $D_{n}$ is the discount factor and $r$ is the discount rate.

${ }^{b} A_{n}=r /\left(1-D_{n}\right)$, where $A_{n}$ is the equivalent annual cost of $£ 1 . D_{n}$ and $r$ as defined above. 
Table 2 Examples of costs attributable to Caesarean section and alternative modes of delivery

Direct Costs
Health care resources
Medical and surgical supplies
Delivery packs
Gowns
Gloves
Masks
Maternity pads
Plastic cord clamp
Spencer Wells forceps
Epidural/anaesthetics
Vitamin K
Mucus extractor
Ventouse machine
Related services
Community midwives
Day care services
General practitioners
Practice nurses
Social workers
Home visitors
Costs to patients and their families/friends
Hospital visiting costs
Additional child care costs

Indirect Costs

Time lost from work due to attendance at antenatal appointments

Time spent by family and friends attending mother and infant in hospital

example, if an item of surgical equipment has a capital cost of $£ 1000$ and has a lifespan of 5 years, and assuming a discount rate of $3.5 \%$, then using the Appendix the 'equivalent' annual cost would be $£ 221.50$ (i.e. equivalent annual cost of $£ 1$ over 5 years $=0.221$ ). In other words, to obtain an annual cost for this piece of equipment you have to spread the capital cost over the lifespan and also account for the discount factor hence $£ 1000$ is 'equivalent' to five annual payments of $£ 221.50$. This higher total cost of $£ 1107.50(5 \times £ 221.50)$ reflects the opportunity cost of capital. Also, when reporting costs they should always be reported in the same year (i.e. adjusting for the effects of inflation). The cost of other related services includes the staffing, supplies, overheads and capital costs associated with ambulance, voluntary and other community services. Productivity costs consist of time lost from work as a result of a health care intervention. See Pritchard and Sculpher ${ }^{7}$ for a recent summary of the estimation of such productivity costs. Considering the types of cost that may be relevant in the reproductive health care area, Table 2 provides an example of costs attributable to Caesarean section and alternative modes of delivery in childbirth, which was adapted from Petrou et al. ${ }^{8}$

\section{Benefit assessment in health care}

In order to explore the cost effectiveness of alternative health care services, both costs and benefits (or health outcomes) must be included within an economic evaluation. The following section outlines the current methods of benefit assessment in health care. Attention is also given to methods of valuing health care benefits (or 'outcomes'). Four benefit assessment tools will be introduced: unidimensional measures of effectiveness, quality-adjusted life years (QALYs), willingness to pay (WTP) and stated preference discrete choice experiments (SPDCEs).

The type of economic evaluation framework used will depend upon the benefit measure used in the evaluation and this topic is considered more fully in the second article in this mini-series. ${ }^{1}$ However, in summary the main methods are cost-effectiveness analysis (CEA), cost-utility analysis (CUA) and cost-benefit analysis (CBA). CEA uses unidimensional measures of effectiveness as its benefit measure; CUA uses utilities, usually in the form of QALYs, as its benefit measure and CBA uses monetary measures of benefit including WTP and SPDCE-derived WTP. It should also be noted at the outset that the principles introduced above, namely discounting and sensitivity analysis, also apply to benefits.

\section{Unidimensional measures of effectiveness}

Definitions of health outcome have varied, ranging from very narrow definitions such as distress and disability to broader definitions, which take account of multiple attributes of health and quality of life. Initial attempts to measure benefits in health economics were mainly clinical in nature and unidimensional (e.g. life years gained, pain reduction, disability days avoided, cholesterol reduction). In the area of family planning and reproductive health, effectiveness measures may include: number of live births achieved, number of pregnancies avoided, breastfeeding weeks, gynaecological infections avoided, and so on.

Farquar et al. ${ }^{9}$ explored the cost effectiveness of preoperative gonadotrophin-releasing analogues (GnRHa) for women with uterine fibroids undergoing hysterectomy or myomectomy in New Zealand. Effectiveness data were obtained from a systematic review from evidence based on 21 randomised controlled trials. The outcome measure used was 'cost per surgical outcome avoided', and the surgical outcomes to be avoided were abdominal hysterectomy and the avoidance of a vertical incision at either hysterectomy or myomectomy. The results showed that for women having a hysterectomy, GnRHa treatment increased the probability of having the preferred vaginal approach from $12 \%$ to $38 \%$, and for those who have an abdominal approach, the probability of the preferred transverse incision increases from $67 \%$ to $84 \%$ with GnRHa. The authors then set these effectiveness measures against the cost data and showed that the cost of avoiding one abdominal procedure was NZ\$4577 per case and the cost of avoiding one vertical incision was NZ\$6263.

Whilst relatively simple to measure and still important, many other important benefits may be ignored using this 'unidimensional' effectiveness approach. For example, where life years are gained in a programme, the quality of such years may be important. More recent work in this area has expanded the definition of health outcomes into the realms of quality of life. The following section on QALYs summarises this development.

\section{Quality-adjusted life years}

QALYs were developed to take account of the fact that an individual may be concerned with the quality of their life as well as the quantity of life. ${ }^{10,11}$ Using QALYs, important health outcomes that would have been difficult to capture with unidimensional outcome measures may be incorporated into the economic evaluation. For example, the effects of suffering infertility from prior chlamydial infection may be captured using QALYs, as these effects will reduce quality of life through unease or depression. To estimate QALYs, expected life years gained from given health care interventions are estimated (either from trial data or information from previously published studies) and combined with information on the quality of these life years, which is estimated either by health care professionals, patients or society. Once important health attributes have been identified, utility weights have to be attached to the various possible outcomes. Quality of life years gained are identified via the estimation of utilities on a scale of ' 0 ' to ' 1 ', where ' 0 ' represents health states equivalent to death and ' 1 ' equates to full health. The most common methods of establishing weights are the standard 


\section{HEALTH ECONOMICS}

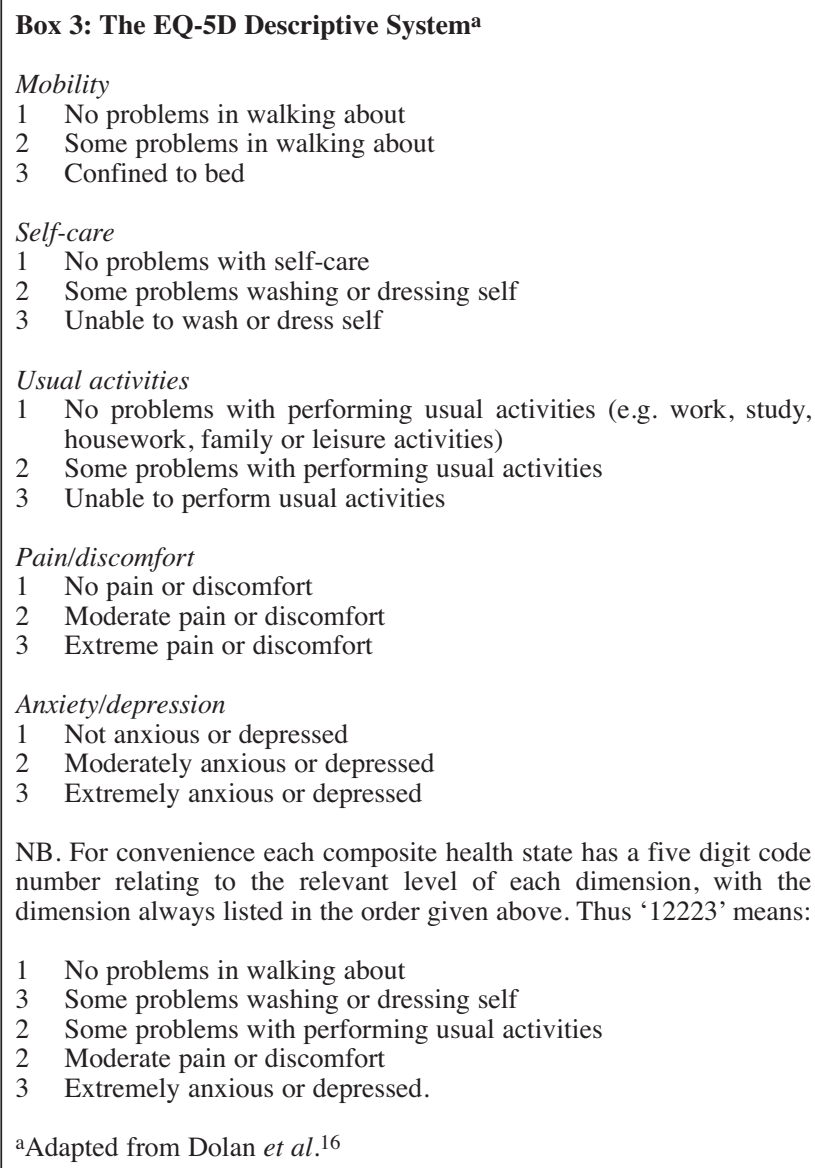

NB. For convenience each composite health state has a five digit code number relating to the relevant level of each dimension, with the dimension always listed in the order given above. Thus ' 12223 ' means:

No problems in walking about

Some problems washing or dressing self

Some problems with performing usual activities

Moderate pain or discomfort

Extremely anxious or depressed.

aAdapted from Dolan et al. . $^{16}$

gamble and time trade-off methods. For a summary of these methods see McNeil et al.,12 Drummond et al. ${ }^{5}$ Torrance and Sackett ${ }^{13}$ and McIntosh and Ryan. ${ }^{2}$

Tools to measure QALYs. Generic measures of utility refer to utility indexes designed to measure attributes of health outcome that are held to be relevant to many types of illnesses and diseases. The original generic QALY proposed two dimensions of health outcome: distress and disability. ${ }^{11}$ More recently the EQ-5D has been developed. ${ }^{10,14,15}$ This takes a multidimensional approach with five attributes, each with three levels. The attributes and levels are shown in Box 3.

The EQ-5D has five attributes each with three levels, giving rise to 243 possible health states. The EQ-5D is now available in 20 language versions. A sample of EQ-5D health states has been valued using a TTO procedure with a large population sample (3337 British adults). From this sample, a regression equation was derived to predict a valuation or 'tariff' for all 243 health states. Using these values it is possible to estimate the utility value for a person in any of the combination of attributes and levels in the EQ$5 \mathrm{D}$ system. ${ }^{16}$ QALYs are then estimated by combining the utility weights for given health states with the duration of that health state. For instance, a patient in a health state of 0.8 (where $0=$ death and $1=$ full health) for 10 years would gain 8 QALYs $(0.8 * 10)$. Discounting this health gain, however, at a rate of $3.5 \%$ would give rise to 6.65 QALYs.

The Short Form 36 (SF-36) is a widely used generic measure of health status in health services research that comprises eight dimensions of health. ${ }^{17-19}$ Recently the instrument has been considered in the health economics literature as a potential generic health classification system and attempts are being made to define possible health outcomes in terms of a single utility score for use in economic evaluations. ${ }^{20,21}$ Generic measures of health outcome have been criticised for being too narrow and insensitive to the outcomes of specific conditions. For example, Donaldson et al. ${ }^{22}$ showed that the use of generic QALYs in assessing the benefits of long-term care for elderly people are not sufficiently sensitive to change in relevant dimensions. They argue that more conditionspecific measures are required. Examples of condition-specific measures include the Arthritis Impact Measuring Scale (AIMS), the Functional Living IndexCancer (FLIC) and the QL-Index, which were developed specifically for use with cancer patients, and the Barthel Index as a single measure of independence in chronically ill patients. For a comprehensive list of generic and disease-specific outcome measures see the online PatientReported Outcome and Quality of Life (PROQOLID) Instruments Database developed by the MAPI Research Institute. ${ }^{23}$

Example of a QALY approach in reproductive health care. Sculpher et al. ${ }^{24}$ carried out a cost-effectiveness analysis of laparoscopic hysterectomy compared with standard hysterectomy (abdominal or vaginal) within a randomised controlled trial. Health benefits were expressed in terms of QALYs gained at 52 weeks' follow-up. The generic EQ$5 \mathrm{D}^{15,16}$ instrument was used to identify utility states from which QALYs were generated. The trial showed that laparoscopic hysterectomy compared to vaginal hysterectomy produced little gains in mean QALYs $(0.0015$, $95 \%$ CI -0.015 to 0.018$)$. The trial also showed that laparoscopic hysterectomy compared to abdominal hysterectomy produced little gains in mean QALYs $(0.007$, $95 \%$ CI -0.008 to 0.023$)$. When these health gains were compared to the additional costs incurred the study concluded that laparoscopic hysterectomy is not cost effective relative to vaginal hysterectomy. The next article in this mini-series ${ }^{1}$ discusses how costs and benefits are combined formally within an economic evaluation framework.

\section{Willingness to pay}

The main feature of the willingness to pay (WTP) approach to benefit assessment is that health outcomes are valued in monetary terms. The technique of WTP is based on the premise that the maximum amount of money an individual is willing to pay (sacrifice) for a commodity is an indicator of the 'value' to them of that commodity. Furthermore, it is argued that when an individual is considering their maximum WTP they will take account of all the attributes of the service of importance to them, not just health gains. Using WTP to estimate the benefits of health care allows individuals to value health outcomes, non-health outcomes and process attributes. ${ }^{25,26}$ WTP can be estimated using four main techniques: open-ended, bidding, payment card and closed-ended.27-29

Example of a WTP study in reproductive health care. There have been a number of WTP studies carried out in this area. ${ }^{26,30-34}$ Many of these studies have attempted to incorporate attributes of importance to the patient beyond those traditionally measured. An example of a typical WTP study in the area of reproductive health care was by Ryan and Donaldson. ${ }^{31}$ The aim of this study was to measure women's preferences for maternity care. The options considered were midwife-managed care versus care in a consultant-led labour ward. Women were asked which type of care they preferred and what would be their maximum WTP for their preferred option. The results showed that most women $(55 \%)$ expressed a preference for care in a midwives unit. However, strength of preference, as 
reflected in the WTP amount, was greater among those in the smaller group, who expressed a preference for care in a consultant-led ward. The authors suggest that the results of the study should be used together with cost data to decide on the most efficient and effective means of providing maternity care.

\section{Stated preference discrete choice experiments}

SPDCEs are becoming more popular in health economics research. ${ }^{35-40}$ The initial stages of a SPDCE are similar to that of the QALY approach (i.e. establish what attributes are important, and what levels to give to them). However, the technique differs from the QALY approach in the way preferences are elicited. Using SPDCEs, preferences are elicited using discrete choices between alternative scenarios. Here the individual is asked to make numerous choices between options, which may vary with regard to health attributes, non-health attributes and process attributes, or any combination of these. Regression techniques are used to analyse the responses, WTP estimates for individual attributes can be estimated when the SPDCE has included 'cost' as an attribute and the results used within a CBA framework. ${ }^{41}$

\section{Discussion}

In this article we have provided a brief overview of economic principles, and the methodological and measurement issues of costs and benefits required for an economic evaluation. However, it is also important for the reader to be aware of some of the general methodological, philosophical and ethical issues associated with the inclusion and measurement of the costs and benefits needed in an economic evaluation. On the cost side, there is much debate on the perspective adopted in the economic analysis. Many economic evaluations in the UK only include in their main analysis the costs incurred (or saved) by the National Health Service, following recommendations by NICE. 4 However, certain interventions might have important financial consequences to the patient or caregiver such as travel and time costs, which will not be taken into account using this narrower perspective. Taking a wider perspective (i.e. societal) will take into account both the direct costs (medical and nonmedical) and the indirect costs (i.e. productivity costs due to mortality and morbidity), potentially capturing all the financial consequences of the different interventions investigated. However, this in not without its controversies. ${ }^{42}$ When a societal perspective is adopted, indirect costs associated with lost productivity due to morbidity (i.e. the days off work due to illness) and premature mortality (i.e. foregone earnings due to early death) are included in the analysis. However, if we include mortality costs in our evaluation, there is counter argument to then include the savings associated with reduced health service costs, or indeed food, clothing and shelter, created by premature mortality, which may seem inappropriate.

There are also issues involving the use of QALYs in economic evaluations. ${ }^{43,44}$ In the area of family planning and reproductive health care the use of QALYs raises many philosophical issues. One of the main issues is the fact that QALYs may not consider all the benefits of an intervention in the area of family planning or reproductive health care. For example, it might be argued that the effects of infertility (i.e. not being able to have a baby when it is wanted) will be captured in the QALY through the effects of depression and anxiety. However, this assumption is highly subjective; for example, if fertility treatment fails, some parents may be able to cope and move on with their lives (i.e. no effect on QALYs), whilst for others their quality of life might be considerably reduced by the failure to have a baby. For other parents, having a baby, even when wanted, may not always lead to an increase in quality of life. If reproduction is achieved through fertility treatment, some parents may experience reduced initial quality of life through parenting due to fatigue or stress due to the demands of a new baby.

Another example where the use of QALYs is controversial is in the area of contraception. In contraception one of the main areas of focus has been in the prevention of unwanted births. In this framework it is assumed that preventing an unwanted pregnancy will increase QALYs. As a result, in previous studies 45,46 more irreversible methods of contraception (such as vasectomy) have been found to be cheaper and more effective (i.e. prevented more pregnancies) than reversible methods of contraception. However, such studies have failed to take into account that people's preferences might change over time. Take a couple, where the man undertakes a vasectomy today to prevent future pregnancies, who might decide 10 years later they want children, but find that they cannot have them due to the consequences of the previous vasectomy, or find that the male has to undergo painful operations to reverse the previous vasectomy, hence reducing his quality of life. Economic evaluations considering contraception should also take into account that a pregnancy may well start as unwanted, but later on in the pregnancy or the birth of the child the pregnancy or child becomes wanted, and hence increases the quality of life of the parent. Therefore economic evaluation in family planning requires careful reflection in terms of design.

\section{Summary}

By outlining the concepts of scarcity, choice, opportunity cost and benefit assessment, and giving examples in the area of family planning and reproductive health care where relevant, this article has provided an introduction to the issues surrounding economic evaluation in health care. This article has also introduced the alternative benefit measures used in economic evaluation in addition to briefly considering their relevance to the area of family planning and reproductive health care. The next article in this miniseries focuses on how the costs and benefits discussed in the previous sections can be brought together within the framework of an economic evaluation. ${ }^{1}$

\section{Editor's Note}

The second article in this mini-series on frameworks for combining costs and benefits in the economic evaluation of health care will appear in the July 2006 issue of the Journal.

\section{Acknowledgements}

The Health Economics Research Centre (HERC) obtains financial support from the National Health Service Research Capacity Development (NHSRCD) programme. The views expressed in this chapter are those of the authors and not NHSRCD

Statements on funding and competing interests

Funding. None identified.

Competing interests. None identified.

References

1 McIntosh E, Luengo-Fernandez R. Economic evaluation. Part 2: Frameworks for combining costs and benefits in health care. J Fam Plann Reprod Health Care 2006: 32: (in press).

2 McIntosh E, Ryan M. Economic evaluation. In: Lawton S, Cantrell J, Harris J (eds), District Nursing: Providing Care in a Supportive Context. London, UK: Churchill Livingstone, 2000; 249-268.

3 Coast J. Is economic evaluation in touch with society's health values? BMJ 2004; 329: 1233-1236.

4 National Institute of Clinical Excellence (NICE). Guide to the Methods of Technology Appraisal. London, UK: NICE, 2004

5 Drummond MF, Stoddard GL, Torrance W. Methods for the Economic Evaluation of Health Care Programmes. Oxford, UK: Oxford University Press, 1987. 


\section{HEALTH ECONOMICS/BOOK REVIEWS}

6 Briggs A, Gray A. Handling Uncertainty When Performing Economic Evaluation of Healthcare Interventions. London, UK: Health Technology Assessment, 1999.

7 Pritchard C, Sculpher MJ. Productivity Costs: Principles and Practice in Economic Evaluation. London, UK: Office of Health Economics, 2000.

8 Petrou S, Henderson J, Glazener C. Economic aspects of Caesarean section and alternative modes of delivery. Best Pract Res Clin Obstet Gynaecol 2001; 15: 145-163.

9 Farquar C, Brown PM, Furness S. Cost effectiveness of pre-operative gonadotrophin releasing analogues for women with uterine fibroids undergoing hysterectomy or myomectomy. Br J Obstet Gynaecol 2002; 109: $1273-1280$.

10 Williams A. The Role of the EuroQol Instrument in QALY Calculations. York, UK: Centre for Health Economics, 1995.

11 Williams A. Economics of coronary artery bypass grafting. BMJ 1985; 291: 326-329.

12 McNeil B, Weichselbaum R, Stephen G, Pauker G. Speech and survival. N Engl J Med 1981; 293: 255-258

13 Torrance GW, Sackett DL. A utility maximising model for evaluation of health care programmes. Health Serv Res 1972; 7: 118-133.

14 Kind P, Dolan P, Gudex C, Williams A. Practical and methodological issues in the development of the EuroQol: the York experience. $A d v$ Med Sociol 1994; 5: 219-253.

15 EuroQol. EuroQol - a new facility for the measurement of healthrelated quality of life. Health Policy 1990; 16: 199-208.

16 Dolan, P, Gudex, C, Kind, P, Williams, A. A Social Tariff for EuroQol: Results from a UK General Population Survey (Discussion Paper No.138). York, UK: University of York, 1995.

17 Ware J, Sherbourne C. The SF-36 short-form health status survey 1 . Conceptual framework and item selection. Med Care 1992; 30: 473-483.

18 Fryback DG, Lawrence WF, Martin PA, Klein R, Klein B. Predicting quality of well-being scores from the SF-36: results from the Beaver Dam Health Outcomes Study. Med Decis Making 1997; 17: 1-9.

19 Veenstra M, Pettersen KI, Rollag A, Stavem K. Association of changes in health-related quality of life in coronary heart disease with coronary procedures and sociodemographic characteristics. Health Qual Life Outcomes 2004; 2: 56

20 Brazier J. The SF-36 health survey questionnaire - a tool for economists. Health Econ 1993; 2: 213-216.

21 Brazier J, Roberts J, Deverill M. The estimation of a preference-based measure of health from the SF-36. J Health Econ 2002; 21: 271-292.

22 Donaldson C, Atkinson A, Bond J. Should QALYs be programme specific? J Health Econ 1988; 7: 239-257.

23 Patient-Reported Outcome and Quality of Life (PROQOLID) Instruments Database. Lyon, France: MAPI Research Institute. http://www.proqolid.org [Accessed 6 February 2006]

24 Sculpher MJ, Manca A, Abbott J, Fountain J, Garry R. Costeffectiveness analysis of laparoscopic hysterectomy compared with standard hysterectomy: results from a randomised controlled trial. $B M J$ 2004; 328: 134-140.

25 Ratcliffe J, Ryan M, Tucker J. The costs of alternative types of routine antenatal care for low risk women: shared care vs care by general practitioners and community midwifes. J Health Serv Res Policy 1996; 11: $135-140$
26 Ryan M. Should government fund assisted reproductive techniques? A study using willingness to pay. Appl Econ 1997; 29: 849.

27 Whynes DK, Frew E, Wolstenholme JL. A comparison of two methods for eliciting contingent valuations of colorectal cancer screening. $J$ Health Econ 2003; 22: 555-574.

28 Zethraeus N. Willingness to pay for hormone replacement therapy. Health Econ 1999; 7: 31-38

29 Mitchell RC, Carson RT. Using Surveys to Value Public Goods: The Contingent Valuation Method. Washington, DC: Resources for the Future, 1989

30 Hundley V, Ryan M, Graham W. Assessing women's preferences for intrapartum care. Birth 2001; 28: 254-263.

31 Ryan M, Donaldson C. Assessing the costs of assisted reproductive techniques. Br J Obstet Gynaecol 1996; 103: 198-201.

32 Ryan M, Hughes J. Using conjoint analysis to value surgical versus medical management of miscarriage. Health Econ 1997; 6: 261-273.

33 Ryan M. Using conjoint analysis to go beyond health outcomes: an application in in-vitro fertilisation. Soc Sci Med 1999; 48: 535-546.

34 San Miguel F, Ryan M, McIntosh E. Demonstrating the use of conjoint analysis in health economics: an application to menorrhagia. Appl Econ 2000; 32: 823-833.

35 Ryan M, Gerard K. Using choice experiments to value health care programmes: where are we and where should we go? Paper presented at the 3rd International Health Economics Association Conference, University of York, York, UK, July 2001.

36 Kleinman L, McIntosh E, Ryan M, Schimer J, Crawley J, Locke GR, et $a l$. Willingness to pay for complete symptom relief of gastroesophogeal reflux disease. Arch Intern Med 2002; 162: 1361-1366.

37 Ryan M, McIntosh E, Shackley P. Using conjoint analysis to assess consumer preferences in primary care: an application to the patient health card. J Health Expectations 1999; 1: 117-129.

38 Ryan M, McIntosh E, Dean T, Old P. Trade-offs between location and waiting time in the provision of elective surgery. J Public Health Med 2000; 22: 202-210.

39 McIntosh E, Ryan M. Using discrete choice experiments to derive welfare estimates for the provision of elective surgery: implications of discontinuous preferences. J Econ Psychol 2002; 23: 367-382.

40 Longworth L, Ratcliffe J, Boulton M. Investigating women's preferences for intrapartum care: home versus hospital births. Health Soc Care Community 2001; 9: 404-413.

41 McIntosh E, Donaldson C, Ryan M. Recent advances in the methods of cost-benefit analysis in healthcare: matching the art to the science. Pharmacoeconomics 1999; 15: 357-367.

42 Weinstein MC, Manning WG. Theoretical issues in cost-effectiveness analysis. J Health Econ 1997; 16: 121-128.

43 Rawls J. Castigating QALYs. J Med Ethics 1989; 15: 143-147.

44 Mooney G. QALYs: are they enough? A health economist's perspective. J Med Ethics 1989; 15: 152.

45 Trussell J, Leveque JA, Koenig JD, London R, Borden S, Henneberry $\mathrm{J}$, et al. The economic value of contraception: a comparison of 15 methods. Am J Public Health 1995; 85: 494-503.

46 Sonnenberg F, Burkman R, Hagerty C, Speroff L, Speroff T. Costs and net health effects of contraceptive methods. Contraception 2004; 69: 447-459.

\section{Book Reviews}

Step-by-Step Ultrasound in Gynecology. K Singh, N Malhotra. New York, NY: McGraw Hill, 2004. ISBN: 0-07-144655-9. Price: £17.99. Pages: 126 (paperback)

This cheap, pocket-sized book's very tempting premise is that it will give readers an overview of all of gynaecological diagnosis and management using ultrasonography. It is written by an ultrasonographer and an obstetrician/ gynaecologist practising in India, and is aimed at a mixed readership. Very short chapters cover the principles of ultrasound and normal female anatomy, before going on to illustration-rich chapters on the ultrasonographic appearance of the normal female pelvis and various uterine and ovarian disorders. Unfortunately the image quality is often poor, and the labelling of the images did not always clarify what was being demonstrated. The most successful images are those that are correlated with findings at hysteroscopy or laparoscopy. I had hoped the accompanying mini-CD-ROM would make the images clearer, but this was not the case. The last chapter has flowcharts for the ultrasonographer illustrating approaches to common gynaecological problems, but these are often not relevant to current UK practice.

Overall, I felt that the style was frustratingly brief for my needs, although ultrasonographers with no gynaecological training may well find it useful.

Reviewed by Pauline McGough, MRCOG, MFFP Subspecialist Registrar in Sexual and Reproductive Health, Glasgow, UK

Prenatal Tests: The Facts. L De Crispigny and F Chervenak. New York, NY: Oxford University Press, 2006. ISBN: 0-19-852084-0. Price: £9.99. Pages: 143 (paperback)

This slim volume is one of a series of medical titles aimed at the public and promising "all the facts you need - straight from the experts". In this case the experts are obstetricians practising in Australia and the USA; the target audience is pregnant women in Australia, the UK and USA.

In these countries, increasingly sophisticated tests are offered to pregnant women; yet the interpretation, risks and benefits of these tests are often misunderstood. Women are asked to make choices about which tests they wish to take - and may have to consider paying for some or all tests.
This book helpfully describes all prenatal tests by stage of pregnancy. Ultrasound is discussed in detail, and there are exquisite images of the normal fetus at various stages of development. Serum screening, amniocentesis and chorionic villus sampling are also discussed at length. Crucially the risks, benefits and limitations are mentioned, stressing that no test can guarantee a healthy baby. There is also a clear glossary to explain technical erms.

The text certainly feels "straight from the experts"; it is clearly written but highly technical and includes details of very rare complications and conditions. I shared this book with one pregnant couple who felt it was readable and clear but rather too detailed for most women. Many women could become highly anxious after reading this book. Conversely, couples grappling with abnormal results or high-risk pregnancies will be much better informed having read this book. It is certainly superior to the random business of surfing the Internet for information. Medical professionals might also appreciate this book and feel better prepared to discuss abnormal results with couples.

Reviewed by Kate Weaver, MB ChB, MFFP Staff Grade Doctor in Reproductive Health Care, Edinburgh, UK 